\title{
Genetics in Medicine inaugurates legal section
}

This issue of Genetics in Medicine contains a new offspring, a section that explores the legal issues impacting on the practice of medical genetics. Some are old issues-such as informed consent, confidentiality, and standards of care-which raise new questions in the context of today's medical genetics practice. Others are relatively new-such as the duty to recontact former patients, technology transfer, and licensure requirements for the practice of telegenetics-and may appear to place substantial, if not insurmountable, burdens on genetics practitioners. Several are uniquely ours, such as genetic testing in children, wrongful birth liability, and the need to balance the confidentiality of the physician-patient relationship against the duty to warn family members of impending genetic risk.
I am delighted to serve as Editor of the new Legal Section, and in that capacity I hope to keep you informed with timely, interesting, and often controversial news and reviews of the legal issues affecting physicians, counselors, scientists, and other individuals and entities who provide clinical and laboratory genetic services and research.

And speaking of timely, interesting, and controversial, the inaugural article of the Legal Section is an overview of the recently implemented federal HIPAA privacy regulations. If you haven't heard about HIPAA yet, let me preface the discussion with my customary disclaimer: Please don't blame the messenger!

Lynn D. Fleisher, PhD, JD Sidley Austin Brown \& Wood Chicago, Illinois 